\title{
TRABALHO E SAÚDE: ESTUDO SOBRE O ADOECIMENTO DOCENTE
}

\author{
TRABAJO Y SALUD: ESTUDIO SOBRE ADOCEMENT DOCENTE
}

WORK AND HEALTH: STUDY ON TEACHING ILLNESS

Vanessa Mariano de CASTRO ${ }^{1}$

RESUMO: A comunicação versa sobre o adoecimento docente mediado pelo materialismo histórico e dialético, de uma revisão bibliográfica e metodologia classificada como estudo descritivo e de revisão de literatura. O material analisado em formato de teses, dissertações e artigos foi acessado através dos bancos de dados CAPES e SciELO, referindo-se ao período de janeiro/2016 a dezembro/2018. Também constam dados bibliográficos de obras de áreas afins referentes ao período de 2008 a 2016. Com abordagem quantitativa e de análise de conteúdo identificaram-se categorias e subcategorias que se relacionaram ao objeto e como resultados propostas louváveis para melhoria da qualidade de vida docente, contudo tais ações se mostram paliativas e pouco pontuais por não resolverem o problema em suas bases fundantes. Nas conclusões pode-se constatar que para reverter esse quadro de adoecimento cabem ações que minem as bases desse sistema que se sustenta na exploração de uma classe sobre a outra.

PALAVRAS-CHAVE: Trabalho. Saúde. Adoecimento docente.

RESUME: La comunicación trata sobre la enfermedad docente mediada por el materialismo histórico y dialéctico, una revisión bibliográfica y una metodología clasificada como estudio descriptivo y revisión de la literatura. Se accedió al material analizado en forma de tesis, disertaciones y artículos a través de las bases de datos CAPES y SciELO, en referencia al período comprendido entre enero de 2016 y diciembre de 2018. También hay datos bibliográficos sobre trabajos de áreas relacionadas para el período de 2008 a 2016. Sin embargo, con un enfoque cuantitativo y análisis de contenido, se identificaron categorías y subcategorías que estaban relacionadas con el objeto y como propuestas dignas de elogio para mejorar la calidad de la vida docente. tales acciones son paliativas y puntuales porque no resuelven el problema en sus bases fundacionales. En las conclusiones, se puede ver que las acciones para socavar este sistema que subyace en la explotación de una clase sobre la otra son necesarias para revertir esta enfermedad.

PALABRAS CLAVE: Trabajo. Salud enseñanza de la enfermedad.

ABSTRACT: The Communication deals with teaching illness mediated by historical and dialectical materialism, a bibliographic review and methodology classified as a descriptive study and literature review. The material analyzed in the form of theses, dissertations and articles was accessed through the CAPES and SciELO databases, referring to the period from January/2016 to December/2018. There are also bibliographic data on works from related

1 Universidade Federal do Ceará (UFC), Fortaleza - CE - Brasil. Mestre em Educação (UFC). ORCID: http://orcid.org/0000-0002-8119-9853. E-mail: vanessamariano@yahoo.com.br

Temas em Educ. e Saúde, Araraquara, v. 16, n. 1, p. 63-83, jan./jun., 2020. e-ISSN 2526-3471. 
areas for the period from 2008 to 2016. With a quantitative approach and content analysis, categories and subcategories were identified that were related to the object and as result praiseworthy proposals for improving the quality of teaching life were proposed, however such actions are palliative and not punctual because they do not solve the problem in their founding bases. In the conclusions, it can be seen that actions to undermine this system that underlies the exploitation of one class over the other are necessary to reverse this illness.

KEYWORDS: Work. Health. Teaching illness.

\section{Introdução}

Esta exposição trata sobre questões que envolvem as condições de trabalho enfrentadas pelos professores no país e quais relações elas teriam com os processos de adoecimento desses profissionais. Desta feita, trabalho e saúde emergem como elementos da totalidade que compõem o ser social e, portanto, têm sua relevância admitida na presente elaboração textual.

Em acordo com o método materialista dialético e metodologia de revisão bibliográfica, uma análise realizada pode ser classificada como um estudo descritivo que se processou a partir de uma abordagem quantitativa e de análise de conteúdo, a fim de identificar categorias e subcategorias que se relacionam aos estudos que fazem referência ao adoecimento docente e levando em conta a criticidade do material coletado, promovida pela observação da realidade com uso do materialismo histórico e dialético ou não.

O levantamento de produções acadêmicas publicadas em artigos foi captado na base de dados Sientific Eletronic Librari Online - SciELO, e de teses e dissertações na Coordenação de Aperfeiçoamento de Pessoal de Nível Superior - CAPES via Portal Domínio Público, referente ao período de janeiro de 2016 a dezembro de 2018. Quanto aos dados bibliográficos, foi empreendido recorte temporal de 2008 a 2016, no tocante às obras publicadas nesse período foram buscadas as categorias e subcategorias atreladas ao trabalho, saúde, educação e adoecimento docente.

Desse modo, sobre os participantes da pesquisa, cabe destacar que foram analisadas 21 publicações, 16 artigos e 5 dissertações publicados nas bases de dados CAPES e SciELO. O universo da pesquisa, as publicações confrontam leituras com viés crítico marxista e outras perspectivas, tendo estas últimas se limitado a descrever realidades pontuais e como descritores de busca utilizados adoecimento docente e adoecimento.

Os dados bibliográficos perpassam, sobretudo, o contexto de uma coleta nas bases de dados SciELO e CAPES em que foram resgatados, respectivamente artigos, teses e dissertações utilizando os descritores adoecimento e adoecimento docente, compondo um total 15 trabalhos 
da CAPES, estando 4 fora do recorte temporal e 6 que fugiam do tema. O que nos levou a uma amostra de 5 trabalhos estudados, sendo que após leitura dos mesmos, 3 foram constatados como leitura marxista da realidade. Sobre a pesquisa da base de dados SciELO de um total de 25 artigos, 9 estavam fora do recorte temporal, portanto dos 16 estudados verificamos que apenas 3 continham viés marxista para análise, restando 13 com outras perspectivas de leitura da realidade.

O que possibilitou desvendar as nuances que perpassam as relações sociais, econômicas e políticas atinentes ao processo saúde-doença, as mediações necessárias ao estudo do trabalho, educação e saúde. Outro ponto nevrálgico, no qual emergiu meu interesse por este tema, foram as conversas informais junto aos professores da rede, nas quais pude verificar a necessidade de coletar dados sobre as principais doenças laborais na contemporaneidade.

Para além do fenômeno aparente, a pesquisa atesta a falta de condições adequadas ao exercício docente e por consequência as manifestações de doenças, já que a realidade empírica disponível pode ser comprovada pelos números expostos nas publicações investigadas, de modo a captar as causas e processos que levam ao adoecimento do docente.

O exame dos fatores que perpassam as relações sociais, econômicas e políticas segue para além da visão biológica e genética da saúde, permitindo abertura à compreensão acerca das repercussões negativas que o sistema capitalista impinge à saúde física e mental dos professores, na forma de patologias relacionadas ao trabalho docente.

O estudo pode vir a ser importante para avaliar as contingências laborais dos professores ao imprimir um retrato da realidade posta ao período examinado, possibilitando analisar e compreender mudanças e transformações ocorridas em meio às demandas e determinações da lógica do capital (MÉSZÁROS, 2008).

Desta feita, formularam-se as seguintes questões para a atividade investigativa: Qual a relação entre trabalho e saúde ao fazer docente? Qual a relação entre o modo de produção vigente e a concepção saúde-doença ao trabalhador docente? Quais causas e consequências do adoecimento docente as propostas possíveis a mudanças significativas?

Apropriado dialeticamente, o objeto de estudo, que é o adoecimento dos professores, possibilitou conhecer as causas e consequências sobre o adoecimento docente, além de apontar que, tanto na base de dados da CAPES quanto da SciELO, há menor incidência de publicações que se apoiem no materialismo dialético para análise, logo pesquisas de viés crítico e marxista, discriminadas por plataforma, temos: CAPES: $20 \%$ marxista contra $40 \%$ não marxista e SciELO: $12 \%$ contra $52 \%$. 
Deste modo, a reflexão promovida pelo objeto levou a considerar que para execução de mudanças significativas é necessária a superação do capitalismo, pois, mesmo a escola sendo instrumento de dominação ideológica da classe hegemônica, ainda assim ela pode ser elemento de superação, tendo em vista o papel singular do docente na apropriação de valores que pleiteiam mudanças no status quo.

\section{A relação entre trabalho, saúde e o fazer docente}

O trabalho emerge como categoria que mobiliza o homem a captar a realidade e a se apropriar dela, de modo a compor esse movimento entre objetividade e subjetividade. Portanto, à medida que o homem transforma a realidade, também transforma a si mesmo, produzindo e reproduzindo novas estruturas e formações de caráter social. Logo, a categoria trabalho se mostra como ontológica e fundante ao ser social e, por sua vez se, apresenta como mediadora de primeira ordem ao processo de consolidação da existência humana, tal como nos é apresentada sua gênese nas ponderações, de modo que:

Antes de tudo, o trabalho é um processo entre o homem e a Natureza, um processo em que o homem, por sua própria ação, media, regula e controla seu metabolismo com a Natureza. Ele mesmo se defronta com a matéria natural como uma força natural. Ele põe em movimento as forças naturais pertencentes à sua corporalidade, braços e pernas, cabeça e mão, a fim de apropriar-se da matéria natural numa forma útil para sua própria vida. Ao atuar, por meio desse movimento, sobre a Natureza externa a ele e ao modificá-la, ele modifica, ao mesmo tempo, sua própria natureza. Ele desenvolve as potências nela adormecidas e sujeita o jogo de suas forças a seu próprio domínio. Não se trata aqui das primeiras formas instintivas, animais, de trabalho. O estado em que o trabalhador se apresenta no mercado como vendedor de sua própria força de trabalho deixou para o fundo dos tempos primitivos o estado em que o trabalho humano não se desfez ainda de sua primeira forma instintiva. Pressupomos o trabalho numa forma em que pertence exclusivamente ao homem. Uma aranha executa operações semelhantes às do tecelão, e a abelha envergonha mais de um arquiteto humano com a construção dos favos de suas colmeias. Mas o que distingue, de antemão, o pior arquiteto da melhor abelha é que ele construiu o favo em sua cabeça, antes de construí-lo em cera. No fim do processo de trabalho obtém-se um resultado que, já no início deste, existiu na imaginação do trabalhador, e portanto, idealmente. Ele não apenas efetua uma transformação da forma da matéria natural; realiza, ao mesmo tempo, na matéria natural seu objetivo, que ele sabe que determina, como lei, a espécie e o modo de sua atividade e ao qual tem de subordinar sua vontade. E essa subordinação não é um ato isolado. Além do esforço dos órgãos que trabalham, é exigida a vontade orientada a um fim, que se manifesta como atenção durante todo o tempo de trabalho, e isso tanto mais quanto menos esse trabalho, pelo próprio conteúdo e pela espécie e modo de sua execução, atrai o trabalhador, portanto, quanto menos ele o aproveita, como jogo de suas próprias forças físicas e espirituais (MARX, 2010, p. 149). 
Desta feita, para esclarecimento teórico pode-se empreender que o trabalho surge como atividade pela qual o homem, constante e necessariamente, transforma a natureza e a si mesmo. Assim, do ato laborativo surge a positividade necessária para agregar conhecimentos à evolução da espécie humana, que cabalmente diverge do estranhamento tipificado na forma de trabalho abstrato $^{2}$ urdido na sociedade capitalista.

Posto que, sob uma nova sociabilidade de apreensão comunista o trabalho se manifestaria em sua forma ontológica, de alienaçã $o^{3}$, ou seja, positiva ao homem, mediante a plena realização pretendida e não conquistada devido à conjuntura afirmadora do estranhamento do modo de produção capitalista. Já que o objetivo de tal organização societal reside na busca de perpetuar a agudização da exploração do homem pelo homem e manutenção da desigualdade, conforme expõe o trecho abaixo:

Este fato nada mais exprime, senão: o objeto (Gegenstand) que o trabalho produz, o seu produto, se lhe defronta como um ser estranho, como um poder independente do produtor. $\mathrm{O}$ produto do trabalho é o trabalho que se fixou num objeto, fez coisal (sachlich), é a objetivação (Vergegenständlichung) do trabalho. A efetivação (Verwirklichung) do trabalho é a sua objetivação. Esta efetivação do trabalho aparece ao estado nacional-econômico como desefetivação (Entwirklichung) do trabalhador, a objetivação como perda do objeto e servidão ao objeto, a apropriação como estranhamento (Entfremdung), como alienação (Entäusserung) (MARX, 2010, p. 80, grifos do autor).

Isso nos permite analisar, que a riqueza do ser genérico deve ser alcançada, a partir do aniquilamento do sentido do ter e a substituição pelo sentido do ser, já que na forma como se apresenta à sociedade posta, a preocupação não está na situação de vida do trabalhador, mas na valorização do valor, para reprodução do capital e, portanto, para a manutenção dos privilégios de uma minoria sobre a maioria, logo na concentração da propriedade privada.

Sendo assim, o ato laborativo efetivo e relacional, enquanto atividade prática histórica, ontológica e tipicamente humana, dentro do modo de produção capitalista torna os indivíduos isolados e competitivos, condições que limitam o ser social a manutenção do poder do ter, tal como o filósofo alemão nos explica:

A propriedade privada nos fez tão cretinos unilaterais que um objeto somente é o nosso [objeto] se o temos, portanto, quando existe para nós como capital

${ }^{2}$ Para Marx este se processa no modo de produção capitalista e condensa ao tempo que agudiza os elementos que negam ao trabalhador a positividade de sua ação, o levando aos estranhamentos de si, entre seus pares, do trabalho e do produto de seu trabalho (MARX, 2010).

${ }^{3}$ Interpretação vertida do alemão da alienação como processo de externação humana, conquistado por meio do trabalho. 
ou é por nós imediatamente possuído, comido, bebido, trazido em nosso corpo, habitado por nós etc., enfim, usado. [...] O lugar de todos os sentidos físicos e espirituais passou a ser ocupado, portanto, pelo simples estranhamento de todos esses sentidos, pelo sentido do ter (MARX, 2010, p. 108 , grifos nosso).

Como cediço, dentro do modo de produção capitalista, pode-se identificar o processo de desefetivação do trabalhador e que, portanto, tal situação o persegue dentro e fora do local de trabalho. Fatos estes, constatados ao verificarmos que este tenta suprir em seu tempo livre a ausência de pertencimento, de quando está em atividade laborativa.

De maneira que este estranhamento, no qual o trabalhador se encontra imerso, o domina material e ideologicamente, fomentando hábitos e necessidades fundadas na manutenção do próprio sistema, já que lhe retira a propriedade de objetivação do espírito como atividade livre e consciente, logo, da positividade do trabalho.

Nessa conformidade o homem sob a condição de estranhamento se vê imerso em uma sociabilidade individualista e meritocrática que o afronta em todo lugar, já que nela perpassa a materialidade de ideologias manipuladas pela classe dominante que se beneficiam da lógica vigente.

Em vista disso, o modo de produção capitalista em consonância com seus reais objetivos, não enaltece o trabalhador, mas o capital. Portanto, essa inversão negativa do processo social, se procede de forma que os indivíduos ao trabalharem retrocedem para as necessidades mais fundamentais como se vestir, se alimentar e habitar, em detrimento do que deveria ocorrer, ou seja, do aprimoramento das habilidades mais sofisticadas.

Deste modo para além do saciamento das necessidades básicas como comer, beber e viver, o trabalho emerge como práxis que transforma a natureza e ao homem, articulando novas capacidades e possibilidades criativas, que sob a égide do sistema capitalista foi subsumida do indivíduo. Ocasionando, conforme Marx (2010), os quatro tipos de estranhamentos que fragilizam e retiram o pertencimento dos seres humanos de suas ações laborativas, fato que a lógica do sistema se impõe aos trabalhadores em todas as esferas da produção, logo o trabalhador docente não está excluído desse processo.

Nesse prisma, trabalho e saúde no desenrolar das mudanças da sociedade e na imanência das contradições do próprio sistema, em se reproduzir à custa da deteriorização da vida na Terra, tem-se a manifestação de discursos que se chocam com a realidade, pois, se por um lado a saúde se afirma como lei:

[...] direito de todos e dever do Estado, garantido mediante políticas sociais e econômicas que visem à redução do risco de doença e de outros agravos e ao 
acesso universal e igualitário às ações e serviços para sua promoção, proteção e recuperação (BRASIL, 1988, art. 196).

No real a saúde, particularmente a dos trabalhadores, é encarada como preocupação secundária, tendo em vista a intensificação do problema da saúde pertinente à categoria dos professores, em que se pode afirmar a necessidade em ser direcionada a luta pela saúde articulada à reivindicação por melhores condições de trabalho.

Desafio a ser enfrentado mediante reivindicação por políticas públicas direcionadas à saúde do trabalhador e levando a discussão, dentre outras pautas emergentes, às escolas em âmbito nacional, no que para Lemos (2011, p. 118) se denomina em chamar a escola, como instituição formadora, assim como a universidade que se cumpra: "tarefa de construção de uma rede que possa assumir umas práxis de resgate dos valores fundamentais do processo educativo emancipador que definem uma instituição como universidade”. Por isso cabe, para esse momento, desvelar a concepção de saúde-doença dentro do modo de produção capitalista para possibilitar a apreensão do real e da situação da educação nesse contexto.

\section{A educação e a concepção saúde-doença sob o jugo do capitalismo}

Da década de 90 aos dias atuais o modo de produção vigente intensificou de tal maneira seu modelo segregador, individualista e meritocrático, a ponto de extrapolar os limites da seara empresarial e chegar às escolas. Deste modo, segundo Bernardo (2014), não tão somente a educação, mas todos os âmbitos da vida humana individual e coletiva sofreram transformações em sua organização social.

Logo, a atividade docente não ficou fora desse contexto, frente a uma realidade de cobranças pautada na flexibilização das atividades produtivas, em que o trabalhador independente da seara de sua atividade se encontra chamado por responsabilidades multisetoriais ou de multitarefas. Para compreender essa lógica de produção e reprodução, que revela o capital, a precarização e as exigências do sistema mediante o produtivismo associado a um trabalho de risco e insalubre, cabe à busca de ir além de uma concepção biologicizante de saúde.

Nesse prisma o professor passa a assumir inúmeros papéis e funções sociais, delegadas pelas instâncias em que o poder público deveria atuar, o que o exige uma postura de equilíbrio e discernimento em diferentes situações, para compreender e não perder o foco da função essencial a que a escola como instituição foi construída, para passar às gerações posteriores o conhecimento historicamente adquirido e acumulado socialmente (SAVIANI, 2005). 
Frente a essa realidade de execução de inúmeros papéis, o professor se encontra sobrecarregado e o adoecimento docente emerge como consequência, pois sua atividade se torna precarizada pela estrutura produtiva, política e ideológica, posta no contexto capitalista, que por sua vez, está pautada nos princípios de competitividade, eficiência e lucratividade, sob esse mérito nos esclarece Salvaro (2009, p. 12):

Acredito que o adoecimento dos docentes só adquire determinado sentido quando analisado no contexto do seu processo de trabalho. Entendo, então, que problemas de saúde possuem componentes amplos e inter-relacionados, que não podem ser avaliados e tratados de forma isolada, devendo-se, no caso, levar-se em conta a complexidade e a dinâmica em que estão inseridos estes docentes. Deve-se considerar então, um caráter multifacetado dos processos de trabalho. Partindo desta ideia, acredito que saúde e doença não são estados ou condições estáveis, mas sim conceitos vitais, sujeitos a constante avaliação e mudança.

Dessa forma, os elementos de intensificação do trabalho e da perspectiva empresarial têm se apoderado sobremaneira da administração pública, logo, a noção da gestão de recursos humanos nas últimas décadas foi priorizada na educação por meio de bonificações ou gratificações aos professores, aferidas conforme o desempenho dos alunos. Tais medidas reforçam o desgaste físico e psicológico dos professores, sobrecarregado em sua atividade laboral, tal como Lemos (2011, p. 108-109) nos elucida sobre as demandas do papel docente:

Uma das consequências das múltiplas atividades do professor, dessa polivalência, é a intensificação e a sobrecarga de trabalho, o que, por sua vez, gera a necessidade de trabalhar no tempo de lazer, com consequências em termos de desgaste físico e psíquico, assim como dificuldades na relação familiar. [...] É o trabalho invadindo o espaço pessoal e privado, impedindo que o professor vivencie outras dimensões da vida, descanse, pense e refaça as energias para enfrentar o cotidiano no início da semana.

Sendo assim, dentre alternativas, a estratégia capitalista do estabelecimento de metas é utilizada com objetivo de pressionar os docentes a não faltarem o trabalho - absenteísmo. Lógica esta que se alastra da educação básica ao ensino superior, tal como amiúde nos esclarece Bernardo (2014, p. 134):

Talvez seja possível afirmar que é nos mecanismos de "administração do poder" que a universidade se aproximou mais dos preceitos predominantes no setor industrial na atualidade. E as metas de produção são, sem dúvida, o mecanismo de administração que pode ser identificado com maior clareza nos relatos dos entrevistados.

Portanto, é perceptível uma inversão de valores, dentro da lógica capitalista de produtividade, quanto ao controle do ensino que oprime e desmotiva os envolvidos, diminuindo 
assim o desempenho profissional dos docentes. De modo essa política de recompensa tem afetado a saúde dos professores, fato evidenciado pela extensa produção acadêmica de pesquisa sobre os problemas de saúde mental e osteomusculares desenvolvidos nos profissionais. Problemas estes responsáveis por quase metade dos afastamentos e por mais da metade do número de dias afastados, fatores que guardam relação intrínseca ao sistema de trabalho, stress, sobrecarga e baixa qualidade de vida. Pensando o adoecimento docente como oriundo, sobretudo das relações e das condições de trabalho, é que se torna importante aprofundar o conhecimento sobre as causas e consequências desse processo, já que segundo Dal Rosso (2008), o ambiente de trabalho docente, por sua organização, exigência, baixa remuneração e falta de estrutura implica em risco à saúde e qualidade de vida, tema por sua vez a ser retomado no tópico seguinte.

\section{Causas e consequências do adoecimento docente: propostas possíveis e/ou mudanças significativas na área}

Como vimos, a precariedade das condições de trabalho do docente se associa a fatores físicos, administrativos, relacionais, pessoais e éticos e, portanto, diante de uma realidade que compõe um cenário de esgotamento físico e mental do docente. Dessa forma, o professor passa a ter que diuturnamente lançar mão de seus recursos biológicos, psíquicos e cognitivos para compensar a falta de recursos e garantir o aprendizado, em concordância ao assunto segue o fragmento exposto por Yonezawa (2008, p. 11):

Entramos constantemente em contato com questões relacionadas à bagunça dos alunos, às dificuldades docentes de despertarem o interesse das crianças para as aulas, à pobreza da comunidade em que está inserida a escola, à violência vivida diariamente pelos alunos em contato com o comércio de drogas, às violências silenciosas sentidas mesmo entre as professoras nas relações institucionais, às dificuldades de aprendizagem, ao excesso de demandas sociais que recaem sobre a escola, especialmente sobre o trabalho do professor.

Nesse cenário o professor paga com a própria saúde a garantia do processo de ensino aprendizagem, pois as relações e as interações ficam em constante estado de tensão, ocasionando excesso de afastamentos dos professores, que por sua vez ao invés de serem interpretados como expressão da precarização da práxis docente, acaba por emergir como um processo invisível. Pois, ao trabalhar mecanicamente, este perde a identificação por sua profissão, gerando um posterior abandono de suas funções, conforme ilustra Silva e Mancebo (2014, p. 491): 
Enfim, no jogo intrincado de uma subjetividade não reduzida e irredutível, indissociável de formas históricas de relações sociais autônomas e heterônomas, do inconsciente capturado, ou, contrariamente, pulsante/não capturável, do imaginário enganoso e do imaginário criativo, florescem deveres distintos, reificações estranhadas e generidade, sempre em movimento, sem nunca haver uma síntese final, sendo o processo histórico expressão e motor deste constante devir, irreversível, e, assim, impossível de ser engessado em uma palavra final.

Desse modo, o comprometimento de suas funções psíquica e afetiva, logo, da subjetividade, chega posteriormente a comprometimentos visualizáveis, ou seja, dos órgãos e funções corporais, como nos relatam o estudo de casos amostrados por diversos autores, que por meio de suas pesquisas relatam o acometimento de doenças como estresse, além de sentimento de indignação e desvalorização, precarização do trabalho docente, sequelas do uso intensivo da voz, síndrome de burnout, produção de conflitos, frustrações, sofrimento e/ou adoecimento docente, portanto, processos de morbidade docente calcados em determinantes ambientais e organizacionais e suas implicações sobre a atividade de trabalho na sala de aula.

Ademais, o excesso e rigor das cobranças, que não vêm acompanhadas das condições necessárias para a realização do trabalho do professor, dentre outros, temos o fomento de estratégias ligadas ao cotidiano escolar que permitam produzir saúde e escapar ao adoecimento em uma população docente que se sente vulnerável e desgastada.

Principalmente em aspectos psicoemocionais e distúrbios de voz, ou seja, do processo de adoecimento, que por sua vez resvalam na vida familiar, amorosa, social, ambiental e profissional, sendo estes associados à perda da qualidade de vida, como sintomas osteomusculares, especialmente na lombar, nos ombros e na região dorsal, que provocam o impedimento de realizar atividades cotidianas, além de situações de mal-estar docente vinculados a processos de adoecimento do corpo e da constituição do psiquismo, tal como estão expressos nas publicações dos autores, Almeida et al., (2011), Piolli (2015), Borsoi e Pereira (2013), Assunção e Oliveira (2009), Oliveira et al., (2012), Pizzio, Klein et al., (2015), Simões (2008) e Bastos (2009).

Pelo exposto, observa-se que dada a falta de políticas em saúde tocantes à prevenção e atendimento médico-assistencial, pode-se aventar a esses problemas a carência de políticas relacionadas à valorização dos profissionais da educação tocante a grande problemática da gestão educacional que por sua vez geram consequências deletérias, segundo Dal Rosso (2011), tanto para a saúde dos professores quanto para a qualidade do ensino, ademais por conta das regras limitantes aos convênios de saúde ou restringindo o acesso a exames diagnósticos e tratamentos necessários. 
Desse modo tornam-se relevantes os estudos sobre propostas possíveis e/ou mudanças significativas na área, dada a necessidade de reconhecimento pelo poder público das doenças afeitas à profissão. No sentido de tratar os profissionais adoecidos com dignidade e urgência a administração pública, ao invés de buscar a resolução para o problema, aplica medidas que pioram ainda mais a situação, como é o caso da premiação por assiduidade, que levam os docentes a trabalharem mesmo adoecidos, por medo de sofrerem prejuízos financeiros.

E até mesmo para correção desse fluxo de afastamentos e evitar essas perdas, elaboramse normas de controle mais rígidas no sentido de se evitar que os trabalhadores faltem ao trabalho. Sobre o prejuízo dessas ações administrativas ao trabalho docente temos a exposição de Paro (2015, p. 85): “[...] Daí o caráter extremamente problemático de alcançar maior produtividade por meio de estímulos pecuniários como à chamada 'remuneração por mérito"”.

Quadro este que, sob a égide da lógica capitalista, costuma imputar do fracasso escolar dos educandos ao adoecimento do docente, justificando que tal fracasso seja pelas ausências do docente, levando a quebras do processo de adaptação e aquisição do conhecimento associado ao processo ensino-aprendizagem. Por sua vez, escamoteando o questionamento sobre as causas do adoecimento docente, ao determinar e direcionar o olhar apenas às consequências, por isso nos chama atenção a necessidade do enfrentamento coletivo de tudo aquilo que envolver o ser professor no Brasil nos dias atuais (GOUVÊA, 2016).

Essa intensificação do trabalho que atinge a classe trabalhadora como um todo e, portanto, também ao trabalhador docente, que o leva ao adoecimento é explicada por Dal Rosso (2008, p. 136):

[...] Quaisquer que sejam as condições de sua realização, o trabalho está sendo transformado pela exigência de mais resultados materiais ou imateriais, o que implica que o agente deva empenhar mais suas energias físicas, mentais ou sociais na obtenção de mais resultados, de mais objetivos, em suma de mais trabalho.

Essas ações emergências partem dos próprios coletivos da categoria, o que resolve paliativamente a situação, contudo fortalece o mecanismo neoliberal de delegar a responsabilidade do Estado aos próprios sujeitos sociais, a solução de problemáticas que deveriam ser diluídas por seus representantes eleitos.

Dentre essas, podemos destacar Almeida (2011) dando visibilidade às ações que transformam positivamente as condições de trabalho na escola, as movimentações cotidianas e suas lutas por saúde. Como exemplo, podemos ilustrar a pesquisa de Pizzio e Klein (2015) desenvolvendo-se o chamado: Qualidade de Vida no Trabalho (QVT), que por sua vez busca 
demonstrar que quanto maior a integração do projeto de vida do docente à instituição, maior é a QVT, mesmo em condições de trabalho desfavoráveis.

Neste sentido coletivizar o fenômeno do adoecimento também significa dar-lhe visibilidade social, a fim de torná-lo uma questão socialmente problematizada e de interesse de toda a sociedade e, portanto, inseri-la definitivamente como tema saúde em destaque na pauta de reivindicações dos trabalhadores da educação na discussão e formulação de políticas educacionais de valorização dos trabalhadores da educação, conforme em detalhe expõe Almeida et al., (2011, p. 258):

A constante luta e movimentos empreendidos pelos sujeitos na produção de saúde no trabalho são emblemas que não podem ser escamoteados ou tornados invisíveis. É imprescindível dar visibilidade à produção de saúde e àquilo que causa sofrimento aos professores em seus ambientes de trabalho. Saúde, portanto, não é um conceito alheio aos sujeitos; os docentes estão autorizados a dizer e a refletir a respeito daquilo que potencializa a atividade e que produz sofrimento patogênico ou paralisante e adoecimento no trabalho.

Nesse prisma as proposições e estratégias referentes à saúde dos trabalhadores da educação devem ser levadas em conta como necessárias para a execução de um projeto de atenção integral, sobretudo prestando a devida atenção desde a prevenção até a assistência, tocante aos aspectos de integridade física, mental e emocional do docente, como condição para a melhoria da qualidade educacional, conforme elucidado no Fórum Nacional de Educação FNE, realizado em 2014.

\section{Sobre os resultados e discussões}

Os resultados coletados e respectivas discussões que constituíram a base da pesquisa realizada sobre o adoecimento docente partiram de uma reflexão sobre o objeto de estudo mediada pelo materialismo histórico e dialético, com auxílio da análise de conteúdo de Laurence Bardin. Deste modo, nos possibilitaram a reconstrução e compreensão da realidade vivenciada ao perfazermos as três fases preconizadas pelo método selecionado que se fundamentam, respectivamente, em pré-análise, exploração do material e tratamento dos resultados (BARDIN, 2010).

Ao que chegamos, resumidamente, a obter, em relação aos descritores (categorias e subcategorias) evidenciados pelo método de análise de conteúdo, no que foi relevante à pesquisa, elencamos dois grupos prioritários, a saber: marxista e não marxista. Desta feita, temos a compreensão do papel do trabalho docente em sintonia com a perspectiva defendida por Dal Rosso et al., (2011) afeta a inclusão deste profissional ao grupo de trabalhadores 
assalariados, em cuja função predomina o trabalho imaterial e atuando como agente de transformação na sociedade.

Quanto às publicações da CAPES a partir dos descritores adoecimento docente e adoecimento, pudemos obter 15 dissertações. Destas, 4 ficaram fora de nosso recorte temporal de 2008-2016, 6 fugiram ao tema proposto e apenas 3 contemplaram leitura crítica marxista do assunto, pois as outras 2 dissertações consideraram uma abordagem não marxista. Para assim podermos ao final constatar a relevância em, não apenas pontuar factualmente a situação existente de adoecimento docente no contexto brasileiro, mas também ponderarmos sobre as causas e consequências, bem como a origem desse processo de adoecimento para vislumbrarmos possibilidades de mudança frente às constatações. Continuando o debate sobre o tema, com viés marxista, analisamos o modo segundo o qual o capitalismo produz corpos e formas de vida no espaço micropolítico da escola, bem como questionamos a abordagem orgânica e médica do problema do adoecimento dos professores, que segundo Yonezawa (2008, p. 11-12):

[...] É sobre a possibilidade concreta de transformação da realidade a partir da concomitante transformação dos modos de sentir e perceber, que falamos neste trabalho. O corpo foi, por isso, nosso ponto de início e de desdobramento, já que nossa intervenção junto às professoras e nossa análise do adoecimento dos professores tiveram como substrato as matérias de expressão, as éticas e as potências produzidas nos encontros entre os corpos.

Retomando o contexto de adoecimento docente na rede pública, mas no âmbito dos professores do ensino fundamental de Minas Gerais, examinamos a pesquisa de Bastos (2009), em que a autora descreve e analisa as situações de mal-estar docente e os processos de adoecimento, em que os principais fatores apresentados pelas professoras, como desencadeadores dos seus processos de adoecimento, estão relacionados à sobrecarga e às condições de trabalho existentes na escola, especialmente a dupla jornada, os baixos salários, a intensificação das funções e das atividades docentes, as novas formas de regulação do trabalho escolar e a avaliação sistêmica do desempenho dos alunos (BASTOS, 2009, p. 7).

Dando continuidade à analise chegamos à pesquisa de Simões (2008) que não se trata especificamente sobre o adoecimento docente, mas foi selecionada por abranger o adoecimento do trabalhador no contexto mais amplo e estando o professor categorizado pelo viés marxista, cabe abrir esse "parêntese" dentro de nossa pesquisa para conceituar e refletir buscando nas palavras do autor: 
[...] compreender a relação existente entre a constituição do mundo psíquico do indivíduo, ou seja, a formação inicial da mente humana, que é subjetiva e inconsciente, e a ocorrência da doença relacionada ao trabalho; que é a doença decorrente do exercício profissional. [...] Em termos de políticas públicas, é possível notar a escassez de serviços especializados para atender a essa demanda. A identificação de tais relações entre o psiquismo e as doenças relacionadas ao trabalho forneceu subsídios para outras formas de apreender as relações que se estabelecem entre saúde e trabalho (SIMÕES, 2008, p. 9).

Detalhando a pesquisa na base de dados SciELO constatamos a presença de 16 artigos publicados, que tal como em busca na base anteriormente analisada cujos descritores apreendidos foram adoecimento e adoecimento docente, temos em realce à compreensão marxista apenas 3 publicações. Lemos (2011) é anunciado por emitir relevo ao processo de precarização e alienação no trabalho dos docentes da Universidade Federal da Bahia, no período de 2005 a 2008. Acerca das conclusões encontradas após sua pesquisa de doutorado, em que constatou a intensificação do trabalho devido, segundo palavras da autora, aos “[...] diversos controles internos e externos do sistema meritocrático, cujas exigências ultrapassam a capacidade física e psíquica do professor para responder adequadamente” (LEMOS, 2011, p. $105)$.

Sobre a subjetividade e adoecimento docente cabe o estudo de Silva e Mancebo (2014, p. 479), ao prestarem referência em que sujeitos da pesquisa são os professores da Universidade Federal Fluminense, cujas principais inferências dos autores inferem:

Diante do trabalho e práticas universitárias verificou-se limites nas formas criativas e singulares de se lidar com adversidades, adoecimento e mecanismos de refração que não redundavam em adoecimento evidente, mas que envolviam fortes conflitos senão cisões subjetivas.

Outra produção, também de contextualização marxista, se inscreve em Bernardo (2014), verificando o chamado "produtivismo acadêmico" como visão de mercado orientadora das diretrizes pertinentes às universidades públicas do Brasil, caracterizando, segundo a autora, a precariedade subjetiva aos docentes e levando ao adoecimento, sobretudo psíquico, devido ao desgaste provocado pela intensificação do trabalho. Em meio a esse processo temos ações pontuais para dissolução do problema, de caráter individual e cotidiano, quando deveriam ser priorizadas ações coletivas.

Sobre as publicações de caráter não marxista temos 13 estudos a detalhar, começaremos por Borsoi e Pereira (2013, p. 1213) cuja análise perpassa o contexto docente universitário, sobretudo em se tratando do "parâmetro de avaliação do desempenho acadêmico individual e coletivo - que parece levar muitos desses professores ao sofrimento e ao adoecimento". 
Nesse cenário, em um contato inicial com a literatura pertinente ao assunto, verificamos que é fato a existência do adoecimento laboral do professor. Pois acostado aos teóricos que investigam a matéria pudemos evidenciar estudos de caso acompanhados da averiguação de pesquisa de campo. Bem como nos oportunizou ir às origens das causas que perpassam as contradições de um sistema com viés segregador, o capitalismo.

Deste modo, a questão de gênero também é associada à realidade docente e está presente nas publicações aqui expostas de forma ampla e geral, e leva ao aprofundamento no estudo de Oliveira et al., (2012), que por meio de um estudo com os professores da área de saúde do ensino superior de Vitória/ES, ao problematizar a condição feminina, o trabalho e o lazer, que pela carência de qualidade de vida levam a consequências como:

[...] distúrbios do sono favorecendo doenças psíquicas; excesso de trabalho; alterações significativas na forma de organização do mesmo, comprometimento da interação social e familiar, com influência sobre a saúde e a qualidade de vida. [...] desenvolvimento do processo de adoecimento, com influência sobre a sua vida familiar, amorosa, social, ambiental e profissional, com perda da qualidade de vida (OLIVEIRA et al., 2012, p.7 41).

Prosseguindo com a questão levantada, que versa sobre a qualidade de vida no trabalho e adoecimento no ensino superior, a pesquisa de Pizzio e Klein (2015), se enquadra neste âmbito, aplicada aos docentes da Universidade Federal de Tocantins, portanto da região Norte do país, tem como diferencial a aquisição da Qualidade de Vida no Trabalho - QVT. Tocante aos resultados amostrados além de outros fatores, destacamos a conclusão:

[...] quanto maior a integração do projeto de vida do docente à instituição, maior é a QVT, mesmo em condições de trabalho desfavoráveis. Por outro lado, quanto maior for o distanciamento do projeto pessoal/coletivo dos objetivos institucionais, menor se torna a QVT" (PIZZIO; KLEIN, 2015, p. 493).

Assunção e Oliveira (2009) salientam a intensificação do trabalho docente ligada ao adoecimento dos profissionais, dados os processos de reformas educacionais ligados aos padrões gerenciais, já mencionados em Piolli et al., (2015), mas agora saindo do ensino superior e abrangendo também a educação básica, elencando, segundo as autoras, os "determinantes ambientais e organizacionais".

Conforme pudemos verificar, as dissertações, teses e artigos amostrados coadunam com padrões que transitam entre descrições epidemiológicas, ergonômicas ou até mesmo de reflexão metodológica crítica, como aos que aventam uma leitura marxista da realidade, e, portanto, utilizam como recurso para exame o materialismo histórico e dialético. 
Desta feita, intensificação, precarização, desgaste, predominância de gênero, sobrecarga, logo, adoecimento são, entre outros temas, constantemente reiterados na escrita dos autores elencados. Fato que não diverge da literatura bibliográfica selecionada, sobretudo quanto nos intérpretes em Mészáros, Paro, Dal Rosso e Saviani que nos atualizam frente a interpretação da realidade contemporânea e os reveses que o sistema capitalista nos coloca, levando ao tema do adoecimento docente.

Segundo Mészáros (2008) há que se evidenciar uma nova sociabilidade para a conquista de relações diferentes de trabalho, para ele o comunismo. Postulado esse que o pensador defende ao levantar a negatividade da alienação como instrumento de doutrinação e internalização da ideologia dominante que se mantém no poder a partir da exploração do trabalho alheio. Conforme nos elucida o filósofo húngaro:

[...] as instituições formais de educação certamente são uma parte importante do sistema global de internalização. Mas apenas uma parte. Quer os indivíduos participem ou não por mais ou por menos tempo, mas sempre em um número de anos bastante limitado - das instituições formais de educação, eles devem ser induzidos a uma aceitação ativa (ou mais ou menos resignada) dos princípios orientadores dominantes na própria na própria sociedade, adequados a sua posição na ordem social e de acordo com as tarefas reprodutivas que lhe foram atribuídas (MÉSZÁROS, 2008, p. 44).

Nesse âmbito se sustenta a realidade e dominação ideológica que o sistema capitalista engendra, e o trabalhador docente como integrante da classe trabalhadora em meio à luta de classes, tal como Paro (2015, p. 74-75, grifos do autor) nos descreve essa relação levando em conta a conceituação marxiana de que o trabalho é uma atividade orientada para um fim, de modo que a correlação de seus elementos, que são a força de trabalho e os meios de que levam ao produto:

Para a reflexão sobre a educação como processo de trabalho, é importante nomear os elementos que estão presentes em todo o trabalho humano, ou seja, os meios de produção [...] e a força de trabalho [...] os meios de produção se subdividem em: objeto de trabalho e instrumento de trabalho. [...] produto que lhe cumpre oferecer: o aluno educado.

Assim, a cultura que é incorporada à personalidade do educando é o que torna o trabalho do educador singular, pois diferindo do trabalho manual, esse exige do docente, sobretudo, esforço intelectual que, ainda segundo mesmo autor e obra, façam despertar o interesse do educando para que aproprie o conhecimento, fruto de conquistas historicamente acumuladas pela humanidade ontologicamente. 
Como também nos esclarece Dal Rosso (2008, p. 144): “O trabalho imaterial produz impactos distintos do material sobre o empregado, devido não apenas ao tipo de serviço realizado, como especialmente às determinações a que sujeita o trabalhador". Segundo Saviani (2006), a escola se configura na contemporaneidade como esse espaço de socialização do saber sistematizado, sendo que a apropriação desse conhecimento sistematizado, mesmos sendo direito adquirido pela classe trabalhadora na contemporaneidade, o sistema reserva para pequena parcela essas aquisições. A começar pelas condições de trabalho do docente da rede pública que o levam a exaustão física e mental, confirmado pelos estudos de caso expostos nos artigos e dissertações evidenciados para essa pesquisa.

Nesse ambiente, o conhecimento sistematizado, cuja garantia deveria ser resguardada à classe trabalhadora, mediante sua disponibilidade na escola pública, se encontra em qualidade aquém das ideais se comparada a escola privada. E, sobretudo em condições que acarretam o adoecimento do trabalhador, tão quanto ou mais que o operário da indústria. Com relação a essas condições de trabalho, que levam ao adoecimento no ato da produção imaterial do professor, incluímos a intensificação do trabalho que o sistema capitalista acentuou nas categorias laborais como um todo. Sobre essa imaterialidade do trabalho docente e as consequências que a intensificação acarreta à saúde do docente e traz consigo grande incidência de atestados, afastamentos, acidentes e doenças (DAL ROSSO, 2008).

A respeito desse processo temos a exposição sobre modelo de gestão por resultados que perpassa os diversos níveis de ensino, da educação básica ao ensino superior, em concordância com os estudos de caso explicitados expressa exigências, por ritmo, velocidade, gestão por resultados e polivalência, consoante ao trecho abaixo. Diferentemente de controle do ritmo e do movimento, gestão por resultados é uma técnica moderna de racionalização do trabalho que permite estimular tanto resultados tangíveis quanto outros tipos de resultados em que estão envolvidos componentes cognitivos e emotivos do trabalhador (DAL ROSSO 2008, p. 191).

Pertinente à revisão de literatura e nos apoiando nos resultados e discussões, pudemos verificar a pertinência de estabelecer a relação entre trabalho e saúde, ao fazer docente temos a composição do trabalho imaterial do professor, segundo Dal Rosso (2008), constando em relevo o profissional da rede pública, mas sem perder de vista o profissional da rede privada.

Nesse contexto de realidade dominada pelo capital, cujo modo de produção se sustenta na agudização da exploração do homem pelo homem, de acordo com Mészáros (2008). De modo que podemos considerar como relevante à pesquisa a intensificação do trabalho docente e alteração da concepção saúde-doença, tal como no exposto abaixo. 
O trabalho docente envolve elementos típicos do desgaste físico, como também de decorrência da pressão por mais resultados. Um bom número das consequências das condições de trabalho docente sobre os professores não apresenta um quadro diferente dos tradicionais problemas sentidos pelos trabalhadores do ramo. [...] Outro conjunto de sintomas declarados, no entanto, revela o efeito do trabalho intelectual prolongado, típico do perfil das doenças decorrentes do trabalho submetido a forte pressão por resultados, com atribuições de responsabilidades, com altos graus de flexibilidade e versatilidade: entre eles estão o estresse, as gastrites crônicas e as lesões por esforços repetitivos (DAL ROSSO, 2008, p. 146).

De modo que temos como fato o adoecimento docente constatado em todos os estudos de caso analisado, frente às causas e consequências de um modo de produção que prima por uma gestão em busca de resultados (PARO, 2015). Também confirmado por artigos e dissertações analisadas, bem como a predominância do gênero feminino na categoria, portanto, em situação persistente de comprometimento da saúde de origem laboral que abrange da educação básica ao ensino superior, confirmando nossa hipótese inicial.

Acerca das propostas sugeridas pelos autores, temos possibilidades de aferições dos níveis de adoecimento e a carência de qualidade de vida dos professores, contudo apenas os estudos com viés pautado no materialismo histórico e dialético é que perfazem uma crítica ao sistema do qual se originam os processos de intensificação e exploração do trabalhador.

Deste modo, nossa reflexão nos levou a considerar que para a formulação de propostas com mudanças verdadeiramente significativas, prescindimos a superação do capitalismo e consagração de outra sociabilidade. Pois, mesmo a escola sendo instrumento deste sistema, mediante a dominação ideológica da classe hegemônica exploradora da classe trabalhadora, ainda assim o papel do docente se torna singular e não em caráter de transmissão, mas de apropriação de valores que pleiteiem mudanças no status quo (MÉSZÁROS, 2008).

\section{Considerações finais}

O presente estudo possibilitou conhecer as causas e consequências sobre o tema do adoecimento docente mediante uma revisão bibliográfica apoiada na compreensão do fenômeno a partir do materialismo histórico dialético e com recorte temporal de 2008 a 2016. A escolha por uma revisão bibliográfica utilizada para este estudo se justifica pela pertinência do tema, dada a confirmação da hipótese de persistência do adoecimento docente, contudo existe apenas uma diminuta quantidade de publicações (artigos e dissertações) que abordam a temática, bem como escassa bibliografia de autores críticos sobre o assunto. 
Dada a verificação das 31 publicações que atenderam aos critérios de inclusão da amostra desta pesquisa, dentre artigos e dissertações coletados da base de dados SciELO e CAPES referente ao período de 2008 a 2016, apenas 6 estudos perpassavam o viés marxista como leitura crítica do objeto estudado. Ao considerarmos como pressuposto para uma leitura crítica sobre a realidade o uso do método de compreensão do materialismo histórico e dialético, temos, portanto, constatado o comprometimento da saúde do professor ocasionada por seu exercício laboral.

Portanto, reforça-se que este estudo não encerra a discussão, mas o oposto disso, realça evidência da indispensabilidade de mais pesquisas para aprofundamento e buscas de respostas que auxiliem na melhor compreensão do objeto estudado, o adoecimento docente. Para assim, projetarmos luzes sobre a persistência das evidências, em busca de alteração e superação da realidade posta, dada a condição verificada pelo autor, essa pesquisa se alinha a perspectiva tratada por Dal Rosso (2008, p. 194):

[...] A imaterialidade do trabalho conduz à observação de impactos novos sobre os corpos e as mentes dos empregados. Como todo tipo de trabalho, os serviços apresentam formas próprias de intensificação que produzem efeitos sobre os corpos e, especialmente, sobre a psique dos trabalhadores. Esta pesquisa propõe grupos de doenças, acidentes e sintomas de adoecimento típicos do trabalho em atividades de serviço intensificadas.

Dito isso, cabe considerar louváveis as ações e proposições das pesquisas, que verificaram projetos para melhoria da qualidade de vida docente, pois são válidos e pertinentes, contudo compreendemos que são ações paliativas e que, portanto, não visam destruir as bases que sustentam a condição de exploração, o sistema capitalista.

\section{REFERÊNCIAS}

ALMEIDA, U. R. Nas trilhas da atividade: análise da relação saúde-trabalho de uma professora de educação física escolar. Trab. Educ. Saúde, Rio de Janeiro, v. 9, supl. 1, p. 245-263, 2011.

ASSUNÇÃO, A. Á.; OLIVEIRA, D. A. Intensificação do trabalho e saúde dos professores. Educ. Soc., Campinas, v. 30, n. 107, p. 349-372, maio/ago. 2009.

BASTOS, J. A. Q. R. O mal-estar docente, o adoecimento e as condições de trabalho no exercício do magistério, no ensino fundamental de Betim/MG. 2009. 149 f. Dissertação (Mestrado em Educação) - Pontifícia Universidade Católica de Minas Gerais, Belo Horizonte, 2009. 
BERNARDO, M. H. Produtivismo e precariedade subjetiva na universidade pública: o desgaste mental dos docentes. Psicologia \& Sociedade, Minas Gerais, v. 26, n. spe, p. 129$139,2014$.

BORSOI, I. C. F.; PEREIRA, F. S. Professores do ensino público superior: produtividade, produtivismo e adoecimento. Universitas Psychologica, Bogotá, Colombia, v. 12, n. 4, p. 1213-1235, 2013.

DAL ROSSO, S. Mais trabalho!: a intensificação do labor na sociedade contemporânea. São Paulo: Boitempo, 2008.

DAL ROSSO, S. et al. Associativismo e sindicalismo em educação: organização e lutas. Biblioteca Sindicalismo em Educação. v. 1. Brasília: Paralelo 15, 2011.

DALAGASPERINA, P.; MONTEIRO, J. K. Preditores da síndrome de burnout em docentes do ensino privado. Psico-USF, Bragança Paulista, v. 19, n. 2, p. 265-275, maio/ago. 2014.

FÓRUM NACIONAL DE EDUCAÇÃO - FNE. O PNE na articulação do Sistema Nacional de Educação: participação popular, cooperação federativa e regime de colaboração. In: CONFERÊNCIA NACIONAL DE EDUCAÇÃO, 2., 2014. Brasília. Anais [...]. Brasília, DF: MEC; FNE, 2014.

GOUVÊA, L. A. V. N. de. As condições de trabalho e o adoecimento de professores na agenda de uma entidade sindical. Revista Saúde Debate, Rio de Janeiro, v. 40, n. 111, p. 206-219, out./dez. 2016.

LEMOS, D. Trabalho docente nas universidades federais: tensões e contradições.

CADERNO CRH, Salvador, v. 24, n. spe 01, p. 105-120, 2011.

MANGO, M. S. M. et al. Análise dos sintomas osteomusculares de professores do ensino fundamental em Matinhos (PR). Fisioter. Mov, v. 25, n. 4, p. 785-794, out./dez. 2012.

MARX, K. Manuscritos econômico-filosóficos. Trad. Jesus Ranieri. 4. ed. São Paulo: Boitempo, 2010.

MARX, K. O Capital: crítica da economia política. Livro I: o processo de produção do capital. Trad. Rubens Enderle. São Paulo: Boitempo, 2013.

MÉSZÁROS, I. A educação para além do capital. Trad. Isa Tavares. 2. ed. São Paulo: Boitempo, 2008.

NORONHA, M. M. B. et al. O sofrimento no trabalho docente: o caso das professoras da rede pública de Montes Claros, Minas Gerais. Trab. educ. saúde, Rio de Janeiro, v. 6, n. 1, p. 6586, mar./jun. 2008.

OLIVEIRA, E. R. A. de. et al. Gênero e qualidade de vida percebida - estudo com professores da área de saúde. Ciência \& Saúde Coletiva, Rio de Janeiro, v. 17, n. 3, p. 741747, mar. 2012.

PARO, V. H. Diretor escolar: educador ou gerente? São Paulo: Cortez, 2015. 
PIOLLI, E. et al. Plano Nacional de Educação, autonomia controlada e adoecimento do professor. Cad. Cedes, Campinas, v. 35, n. 97, p. 589-607, set./dez. 2015.

PIZZIO, A.; KLEIN, K. Qualidade de vida no trabalho e o adoecimento cotidiano de docentes do ensino superior. Educ. Soc., Campinas, v. 36, n. 131, p. 493-513, abr./jun. 2015.

SALVARO, M. S. Processo de trabalho docente: relação entre o ser e o adoecer. 2009. 110 f. Dissertação (Mestrado em Educação) - Universidade do Extremo Sul Catarinense, Criciúma, 2009.

SAVIANI, D. Pedagogia histórico-crítica: primeiras aproximações. 9. ed. Campinas, SP: Autores Associados, 2005.

SAVIANI, D. Escola e democracia. 38. ed. Campinas, SP: Autores Associados, 2006.

SILVA, E. P. E.; MANCEBO, D. Subjetividade docente na expansão da UFF: criação, refração e adoecimento. Fractal, Rev. Psicol, Rio de Janeiro, v. 26, n. 2, p. 479-492, maio/ago. 2014.

SILVA, S. A. da.; PAES, M. S. L. Caracterização do absenteísmo dos docentes da rede municipal da rede municipal de Coronel Fabriciano - MG. Revista Enfermagem Integrada, Ipatinga: Unileste, v. 9, n. 1, jul./ago. 2016.

SIMÕES, F. I. W. A constituição do mundo psíquico e as doenças relacionadas ao trabalho. 2008. 173 f. Dissertação (Mestrado) - Universidade Estadual Paulista, Assis, 2008.

VILELA, E. F. et al. Vivências de prazer-sofrimento no trabalho do professor. Revista Eletrônica de Administração - REAd, Porto Alegre, ed. 75, n. 2, p. 517-540, maio/ago. 2013.

YONEZAWA, F. H. Corporeizar: Acompanhar o problema do adoecimento das professoras a partir de uma intervenção ético-afectiva em grupos. 2008. 198 f. Dissertação (Mestrado em Educação) - Universidade Federal do Rio Grande do Sul, Porto Alegre, 2008.

\section{Como referenciar este artigo}

CASTRO, Vanessa Mariano de. Trabalho e saúde: estudo sobre o adoecimento docente. Temas em Educ. e Saúde, Araraquara, v. 16, n. 1, p. 63-83, jan./jun., 2020. e-ISSN 2526-3471. DOI: https://doi.org/10.26673/tes.v16i1.13489

Submetido em: 25/01/2020

Revisões requeridas: $22 / 03 / 2020$

Aprovado em: 18/05/2020

Publicado em: 19/06/2020 